\title{
FFM 1200. Traditionen und Perspektiven einer Stadt et 794. Karl der Große in Frankfurt am Main
}

Pierre Monnet

\section{OpenEdition}

\section{Journals}

Édition électronique

URL : http://journals.openedition.org/ifha/1979

DOI : 10.4000/ifha.1979

ISSN : 2198-8943

\section{Éditeur}

IFRA - Institut franco-allemand (sciences historiques et sociales)

Référence électronique

Pierre Monnet, «FFM 1200. Traditionen und Perspektiven einer Stadt et 794. Karl der Große in Frankfurt am Main », Revue de l'IFHA [En ligne], Date de recension, mis en ligne le 01 janvier 1994, consulté le 22 septembre 2020. URL : http://journals.openedition.org/ifha/1979 ; DOI : https://doi.org/ 10.4000/ifha. 1979

Ce document a été généré automatiquement le 22 septembre 2020.

(C)IFHA 


\title{
FFM 1200. Traditionen und Perspektiven einer Stadt et 794. Karl der Große in Frankfurt am Main
}

\author{
Pierre Monnet
}

Francfort-sur-le-Main commémore cette année un grand jubilé: le douze-centième anniversaire de la première mention écrite de la ville de Francono furt dans un document carolingien daté du 22 février 794 et adressé à l'abbaye Saint-Emmeran de Ratisbonne. A cette occasion, deux expositions accompagnées chacune d'un riche catalogue célèbrent cette date de naissance officielle d'une ville que les Romains avaient déjà équipée d'une villa rustica dès 110 ap. J.-C.

La première exposition intitulée "Charlemagne à Francfort" s'est tenue dans le Musée Historique de Francfort. Elle décline en neuf grands thèmes le contexte politique, intellectuel, religieux et économique qui entoura la réunion, au cours de l'été 794, d'un synode général. Le choix du lieu n'est pas fortuit: il s'agissait alors pour le Carolingien de consolider tout un glacis de villes et de forts sur les marches orientales de l'Austrasie, et Francfort, entre Mayence et Fulda, constituait un des points d'ancrage et de ravitaillement importants des campagnes militaires de l'Est. La date non plus n'est pas fortuite: les Danois s'apprêtaient à conquérir l'Angleterre, la Saxe était en révolte, une armée sarrasine était entrée en Septimanie, si bien qu'était nécessaire une manifestation renouvelée, à la fois politique et spirituelle, de l'autorité du souverain.

L'exposition tout entière constitue une explication du capitulaire de Francfort de 794 et du monde qu'il reflète. Sept grandes questions étaient à l'ordre du jour, pour la plupart déjà mentionnées dans l'admonitio generalis de 789 et reprises dans l'exposition à travers toute une série d'objets et de manuscrits répartis en quatre salles: la menace d'hérésie venue de l'Espagne musulmane (l'adoptianisme); la querelle des images à la suite des décisions du concile de Nicée de 787 (favorable au culte des images); la destitution du duc de Bavière Tassilon II (intervenue six ans plus tôt et reconnue légitime par le synode); la création d'une nouvelle mesure publique de compte (modius publicus); la réforme monétaire; la formation des prêtres, le respect des règles par les 
moines, le règlement des conflits entre clercs et laïcs; enfin l'utilisation des langues vernaculaires pour la prédication et la diffusion de la vraie foi auprès du peuple. Ce faisant, Charlemagne renforçait son autorité en étoffant le pouvoir régalien et tentait d'affirmer son statut de chef spirituel de la chrétienté.

La seconde exposition se présente pour sa part sous une forme plus classique que la première et retrace en dix salles le destin et la croissance du "gué des Francs" (Franken-Furt). L'histoire du site que restitue la première salle montre bien que la géographie combine ici à la fois les fonctions de passage et de défense propres à toute frontière fluviale. L'épisode carolingien, auquel l'exposition »794« accorde toute la place nécessaire, est passé plus rapidement en revue; le temps des Ottoniens et des Saliens est un moment d'oubli. La seconde salle aborde ensuite le temps de la ville bourgeoise et restitue le processus de croissance qui, à partir du milieu du XIIe et surtout au XIIIe s., s'appuie sur un retour de faveur des empereurs décidés à faire de la ville un lieu de défense mais aussi de commerce. L'exposition montre bien l'épanouissement à l'ombre de l'Empire d'une civilisation patricienne et marchande conduite par une élite restreinte de la fortune et du pouvoir qui occupe sans partage les bancs du Conseil municipal; l'éloignement de l'Empereur à la fin du Moyen Age supprime ce facteur favorable et montre une ville rivalisant difficilement avec Nuremberg. La troisième salle met en relief la prospérité retrouvée des foires à partir de la seconde moitié du XVIe s., en particulier grâce au commerce des livres et du change. L'un des traits frappants de cette histoire est l'extraordinaire continuité du pouvoir patricien au Conseil urbain: une aristocratie sénatoriale riche, fermée mais cultivée, dont Goethe fit la critique mais dont il fut au demeurant un assez fidèle représentant. La fin de l'exposition retrace assez bien, dans ses paradoxes et ses contradictions, l'explosion à la fois économique et sociale au sein d'une ville jusqu'alors presque sans histoire: entre 1875 et 1905, Francfort, la ville libre du grand et raisonnable patriciat d'affaires, devient un des avant-postes du combat socialiste et démocratique, un des lieux de l'avant-garde culturelle de Weimar. Le nazisme introduit une coupure brutale entre la ville et son histoire, en en faisant anachroniquement une "capitale de l'artisanat allemand«, en décimant la communauté juive de la ville natale des Rothschild, en conduisant à sa destruction (la maquette exposée dans la dernière salle montre l'ampleur matérielle du désastre qui anéantit plus de $70 \%$ du centre ville). On retrouve aujourd'hui très peu du passé urbain dans une cité devenue vitrine du miracle allemand de la reconstruction, capitale de la grande finance. Cette exposition vient à propos rappeler que la prospérité d'aujourd'hui ne repose toutefois pas seulement sur le travail d'une génération, mais plonge ses racines dans une vieille tradition d'échanges et d'ouverture. 